\title{
AS FESTAS RELIGIOSAS, O PROFANO NO SAGRADO: formação dos professores
}

\section{The religious parties, the sacred in profane: training for teachers}

\section{Luiz Alberto Sousa Alves ${ }^{a}$, Sérgio Rogério Azevedo Junqueirab}

a Mestre em Educação pela Pontifícia Universidade Católica do Paraná (PUCPR), Professor do Curso de Bacharelado em Teologia da Pontifícia Universidade Católica do Paraná (PUCPR), Membro do Grupo de Pesquisa Educação e Religião (GPER), Curitiba, PR - Brasil, e-mail: luizalberto.salves@gmail.com

b Doutor em Ciências da Educação, Universidade Pontifícia Salesiana de Roma (Itália), Líder do Grupo de Pesquisa Educação e Religião (GPER), Professor do Programa de Pós-Graduação em Teologia da PUCPR, Curitiba, PR - Brasil,e-mail: srjunq@uol.com.br

\section{Resumo}

O texto apresenta o papel das festas nas tradições religiosas que apresentam elementos como mito, rito, símbolo, música, dança, luxo e beleza. Na busca de construir a leitura religiosa da sociedade, favorecendo articulação de uma nova configuração do Ensino Religioso. Por exemplo, o mito é a primeira tentativa do homem para entender o cosmos e a vida. Como ainda não tinham desenvolvido uma ciência natural que lhes ajudasse a compreender toda essa complexidade, o homem criou os mitos, que se constituem numa ferramenta poderosa de explicação do macro e 
microcosmo, os mitos são histórias que, contadas e ouvidas, suscitam a reflexão sobre o tema abordado. Outros aspectos podem ser compreendidos nesta ampla perspectiva. A festa com todos os seus elementos têm a função de tornar a vida humana mais leve e fácil de ser vivida. Ela ajuda a comunidade a confiar na sua capacidade de organização e realização de seus projetos. A estrutura da festa se relaciona também com a estrutura da vida das pessoas no seu cotidiano.

Palavras-chave: Mito. Tradição religiosa. Educação. Ritos. Festas.

\section{Abstract}

This text presents the role of festivities in religious traditions that presents elements such as myth, symbol, music, dance, luxury and beauty. Seeking to build a religious understanding of society favoring articulation of a new configuration of religious education. For example, the myth is the first attempt of man to understanding of cosmos and life. Since man does not had developed a natural science that could help to understand all this complexity, he created the myths that are a powerful tool of explanation of macro and microcosmos, the myths are tales that narrated and listen raise a reflection about the theme approached. Others aspects can be understand in this wide perspective. The festivities and all its elements has a function of making the human life easier and lighter to be lived.

Keywords: Myth. Religious tradition. Education. Rites. Festivals.

A partir da Lei de Diretrizes e Bases da Educação Nacional (LDBEN) $n^{0}$ 9394, de 20 de dezembro de 1996, posterior alteração do artigo 33 pela Lei n ${ }^{0}$ 9475 de 22 de julho de 1997, diferentes tendências foram acentuadas quanto à compreensão do Ensino Religioso no Brasil como disciplina do currículo escolar.

As interpretações em relação ao dispositivo legal suscitaram novos questionamentos e ponderações, que se somaram à antiga problemática da formação de profissionais da educação para o exercício docente desta disciplina. Isto é, a formação de educadores de Ensino Religioso e a garantia de seus direitos como profissionais integrados ao quadro do magistério público.

Rev. Pistis Prax., Teol. Pastor., Curitiba, v. 1, n. 2, p. 435-442, jul./dez. 2009 
O artigo $n^{\circ} 33$ da LDBEN, em seu primeiro parágrafo, indica que a orientação sobre habilitação e admissão dos professores para o Ensino Religioso é de competência dos sistemas de ensino, que poderão ser estaduais ou municipais. [...] $\S 1^{\circ}$ - Os sistemas de ensino regulamentarão os procedimentos para a definição dos conteúdos do Ensino Religioso e estabelecerão as normas para a habilitação e admissão dos professores [...] (BRASIL, 1997, p.1).

Os responsáveis pela formação de docentes para o Ensino Religioso na atualidade brasileira, atentos às exigências legais em um espaço tecido em diversidade cultural e marcado por histórias de invasões e resistências nas mais diferentes áreas, debruçaram-se em buscar formas de construir referenciais e práticas formadoras para atender o édito legal.

Entre os eixos formadores, encontra-se a questão da leitura cultural do fenômeno religioso para que este seja refletido aos estudantes no cotidiano da sala de aula (OLIVEIRA et al., 2007, p. 58-60). Nessa perspectiva, um dos elementos a serem explorados na formação são as festas que fazem parte do calendário e rotina em nossa sociedade.

Explicitemos esta leitura das manifestações culturais do povo brasileiro, como por exemplo o carnaval, a festa das festas, que muitos aguardam e se preparam o ano inteiro para o seu acontecimento. O carnaval, por sua estrutura e importância, tem uma relação muito íntima com o sagrado. Para alguns, essa afirmativa pode não ter muito sentido, mas, ao analisarmos a função das festas, que pela sua estrutura aparentemente está mais ligada aos aspectos ditos profanos da nossa existência e, portanto, para alguns pode representar a manifestação do mal, veremos sua grande importância na vida dos homens e das próprias tradições religiosas. Entender a importância da festa a partir da perspectiva do sagrado nos remete à discussão doutrinal presente na teologia das grandes tradições religiosas sobre a existência.

Se acreditarmos que Deus é o autor da criação, e que tudo que ele cria é bom, se Deus está acima do tempo, realidade aplicada somente a nós seres encarnados, quando Ele cria, tem consciência da totalidade da criação, então se pergunta: Por que Deus permitiu a existência do Mal nas suas mais diversas manifestações? Simplificando o questionamento, sem entrar nas questões mais profundas da teologia, partindo do princípio de que a função da religião é tornarmo-nos humanos, e que na maioria das tradições religiosas se afirma o princípio doutrinal do livre arbítrio, ou seja, somos seres criados para a liberdade, o mal então é percebido como o elemento desafiador para os indivíduos, uma

Rev. Pistis Prax., Teol. Pastor., Curitiba, v. 1, n. 2, p. 435-442, jul./dez. 2009 
vida sem desafio é uma vida vazia, despojada de projetos e significados. O mal faz parte da nossa existência como forma de desafio, nunca como sentido da vida; temos que conhecê-lo para podermos combatê-lo, ele faz parte da complexidade que é viver. Daí que compreendermos a importância das festas dentro das tradições religiosas, apesar da sua aparência profana e, talvez para alguns, maléfica, é fundamental, e para tanto iniciamos esta reflexão com Durkheim (1996, p. 351), esclarecendo que:

Toda festa, mesmo que seja puramente leiga em suas origens, possui certas características de cerimônia religiosa, pois tem por efeito aproximar os indivíduos, colocar massas em movimentos e suscitar assim um estado de efervescência, algumas vezes mesmo em delírio, que não é sem parentesco com o estado religioso.

Nelas o sagrado e o profano estão tão entrelaçados que às vezes é quase impossível separá-los e distingui-los.

As festas, tal como as tradições religiosas, apresentam elementos como mito, rito, símbolo, música, dança, luxo e beleza. O mito é a primeira tentativa do homem para entender o cosmos e a vida. Como ainda não tinham desenvolvido uma ciência natural que lhes ajudasse a compreender toda essa complexidade, o homem criou os mitos, que se constituíram numa ferramenta poderosa de explicação do mundo e da vida. Os mitos são histórias que, contadas e ouvidas, suscitam a reflexão sobre o tema abordado. Mito e rito se completam, o rito é um arranjo de símbolos, uma representação da estrutura social, uma orientação da ação dos indivíduos no grupo, uma teatralização do mito, o rito deslocado do símbolo fica descaracterizado e sem nexo. Os símbolos são chaves que abrem portas para o incognoscível, o símbolo pode ser chamado de sinal por apontar para algo, ajuda a entender o incompreensível, a perceber o impercebível, mesmo quando ele está evidente, por isso que num espetáculo, seja num teatro, num cinema, num estádio, numa liturgia e num desfile de escola de samba, se não dominarmos a linguagem simbólica presente, vamos achar tudo lindo e maravilhoso, mas não seremos tocados, porque não compreendemos nada (CAMPBELL, 2004, p. 59-62).

A música é o grande tempero da vida, ela nos eleva, deprime, excita, acalma, torna-nos anjos ou demônios. É uma ferramenta poderosa por nos tocar e ajudar para que a vida se torne mais leve, amenizando os problemas e sofrimentos, por isso está em nossa história desde os primórdios; cantamos na alegria, na tristeza,

Rev. Pistis Prax., Teol. Pastor., Curitiba, v. 1, n. 2, p. 435-442, jul./dez. 2009 
na vitória, na derrota, no nascimento, na morte, na perda e no ganho, como diz o povo, ‘quem canta seus males espanta'. Há música para todos os momentos e acontecimentos da vida, a música está presente nos acontecimentos sagrados e profanos, se não existisse a música nossos cultos e liturgias não teriam graça, não falariam à vida. A música sem a dança ficaria pobre, a dança é a maneira de o corpo interagir com a música, é a maneira de extravasar e quebrar as couraças que a vida e o cotidiano insistem em colar em nosso corpo, se o corpo é um espaço sagrado, por ser criação de Deus, por que ficar cheio de rigidez e couraças?

A dança quebra essas couraças e rigidez, pois, dançando, movimentamos a energia da vida presente em nós, que o cotidiano castrador insiste em querer apagar. A música e a dança ligam, integram e religam. Ligam o homem a si mesmo, dando consciência do seu corpo e, consequentemente, dos seus limites, couraças e rigidez, impulsionando-o na superação; integram o indivíduo a seu semelhante, dançamos com o outro, mesmo quando se dança sozinho, a dança tem algo de coletivo, porque é na vida em grupo, em comunidade que nos tornamos fortes na superação das dificuldades que o meio insiste em colocar em nossos caminhos, o homem é um ser para o outro, não fomos criado para nós mesmos, no tornamos humanos em grupo (CAMPBELL, 2004, p. 75-77). A música e a dança nos religam a nós mesmos, ao coletivo, ao cosmos, ao transcendente, a Deus, pois ele nos ajuda na superação dos limites, mantendo acessa a crença na força da vida.

Não existe festa e liturgia sem alimentos e bebidas, o corpo precisa desses elementos para se fortalecer para a longa jornada que é o viver, um corpo sem alimento se fragiliza, o fraco no primeiro obstáculo fenece, desiste, por falta de forças, o ato de comer e beber fortalece os laços de união do grupo, tanto familiar como comunitário. A comida é a base do sustento da vida biológica, por isso a sua preparação é sagrada, quem prepara a comida interage com ela, transmitindo seus sentimentos e energia, daí antigas culturas (o que infelizmente foi perdida na cultura atual) adotarem regras de pureza para quem preparava os alimentos, conhecimento ainda hoje preservado no Candomblé. A bebida (com teor alcoólico) serve como elemento desinibidor, relaxante, socializador, que ajuda a quebrar os formalismos e as máscaras sociais que usamos em nosso cotidiano. É importante destacar o uso de maneira equilibrada da comida e da bebida, o excesso é prejudicial, por perder de vista o seu objetivo, todo extremo é desestruturante e pernicioso, daí as tradições religiosas sempre apontarem para o equilíbrio entre os extremos.

Rev. Pistis Prax., Teol. Pastor., Curitiba, v. 1, n. 2, p. 435-442, jul./dez. 2009 
Nas festas, o luxo e beleza se fazem presentes por serem elementos mantenedores dos sonhos e esperanças, uma vida feia, sem glamour, é esvaziada de sentidos, é esvaziada de sonhos e esperanças, é uma vida que se vai levando até chegar-se à morada final, se morremos como vivemos, uma vida despojada de beleza encontrará uma morte muito feia, o que será realmente o fim porque, em vida, a esperança foi aniquilada. A beleza deixa a vida mais leve, mais fácil de ser vivida, ameniza a rudeza do cotidiano, ajuda-nos a extravasar os sentimentos ruins que fomos cultivando em nosso dia-a-dia, daí encontrarmos obras de arte nos templos, o que, aliás, apenas tenta representar as maravilhas existentes na natureza, que o estilo de vida atual tirou-nos, isto é, a capacidade de contemplação dessa grande maravilha criada por Deus. Quase toda festa pressupõe sexo, mas, como em nossa cultura ele foi varrido para debaixo do tapete doutrinal e da moralidade, acabou virando tabu, algo proibido. Infelizmente, para muitas pessoas o sexo foi esvaziado de seu sentido divino, transformando-se num jogo de poder e dominação. Sexo é a continuidade da vida, é o encontro e o congraçamento que pressupõe a conquista, o diálogo, o respeito, a aceitação e o consentimento. Algumas tradições religiosas (indianas, africanas e nativas) trazem em seus arcabouços doutrinais vários conhecimentos sobre o sexo e o erotismo como formas sagradas presentes na vida, como caminhos de espiritualidade.

A festa é importante por transmitir à comunidade que a realiza a consciência da sua capacidade de organizar e gerenciar a vida, por mais difícil e complexa que ela se apresente, festa sem organização vira fiasco, daí entendermos toda a estrutura e mobilização que movimentam as escolas de samba do Rio de Janeiro, a comunidade sente orgulho da sua escola, por projetar nela as suas angústias e esperanças. O ápice da escola de samba é o desfile, o qual precisa ser pensado, organizado e preparado com grande antecedência, ou a escola 'pagará mico’ na avenida e será rebaixada de grupo, o que se constitui numa grande perda e decepção para todos. É preciso pensar no samba enredo, o mito, que irá contar uma história no dia do desfile. A escola é dividida em alas, o rito, que contarão de maneira teatralizada e simbólica o tema do samba enredo; essas alas trarão carros alegóricos e foliões com fantasias luxuosas e bonitas, como representação de um ideal de vida, por mais que no dia-a-dia essa vida teime em se apresentar de maneira feia, com suas exclusões, violências, fome, desemprego, miséria... Vale a pena sonhar que amanhã a vida deixará de ser sapo e se transformará em um belo príncipe.

Rev. Pistis Prax., Teol. Pastor., Curitiba, v. 1, n. 2, p. 435-442, jul./dez. 2009 
As tradições religiosas fazem parte da existência dos homens por se constituírem na primeira ferramenta da nossa humanização. Desde sua origem, as religiões procuram humanizar os homens, afastando-os dos determinismos biológicos, geográficos e culturais, é por meio da percepção do sagrado que a vida foi se estruturando, a religião foi a primeira a utilizar os mitos como ferramenta para a compreensão da vida, os mitos serviram de base para os textos sagrados que estruturaram a organização pessoal e social dos homens, as religiões propiciaram a estes homens um processo de descobertas, primeiro da finitude, fazendo-os perceber que a morte faz parte da vida, e que em vida iremos morrer várias vezes para propiciar o nascimento de um homem novo, tal como a fênix. Segundo a descoberta de que em nós existe um lado sapiens e outro demens, temos de conhecêlos e reconhecê-los não para eliminá-los, mas aperfeiçoá-los e superá-los, pois a vida é um processo contínuo de aprendizado, em que o ser religioso é aquele que sabe reconhecer seus potenciais e seus limites como meio de manter uma relação equilibrada com o seu semelhante, pois aquele que conhece seus potencias não se sente ofuscado com o potencial do outro, aquele que reconhece seus limites, é mais compreensível com o limite do próximo, não significando entretanto que ele tenha que aceitar esses limites, pois aí está a beleza das tradições, que orienta na superação constante desses limites, tanto no plano individual como coletivo, objetivando a humanização dos indivíduos e, consequentemente, estruturando o grupo social para possibilitar uma vida digna e justa nos moldes do paraíso, que significa um lugar onde o mal não existe (ELIADE, 1977, p. 69-71).

Na sua função civilizadora, as tradições apontam as características do homem religioso. Ser religioso é vivenciar a regra de ouro, comum a todas as tradições religiosas, 'Não faças aos outros, o que não queres que te façam', o ser religioso é aquele que pratica o amor, a justiça, a caridade, a benevolência, a compaixão, a humildade, a alteridade... Ser religioso é reconhecer a beleza da vida, é admitir a nossa condição de aprendizes, sendo que aprendiz é aquele que descobre que a vida é extremamente dinâmica, que fazem parte dela a alegria e a tristeza, a saúde e a doença, perdas e ganhos, a felicidade e o sofrimento... e que, se soubermos aprender com esses princípios contraditórios, estaremos mais bem preparados para esta longa jornada que é viver.

A partir desses elementos, provocaremos uma releitura do ser religioso no cotidiano da sociedade, favorecendo a professores e estudantes da educação básica uma compreensão mais ampla dos elementos que compõem a educação do profano e do sagrado nas ações individuais coletivas. 


\section{Referências}

BRASIL. Lei n. 9.475, de 22 de julho de 1997. Da nova redação ao artigo 33 da lei 9.394, de 20 de dezembro de 1996, que estabelece as diretrizes e bases da educação nacional. Diário Oficial da União, Poder Legislativo, Brasília, DF, 23 jul. 1997. p. 15824. Disponível em: <http://www6.senado.gov.br/legislacao/ ListaPublicacoes.action?id=146598>. Acesso em: 15 jul. 2009.

CAMPBELL, J. As máscaras de Deus: mitologia ocidental. São Paulo: Pala Athena, 2004.

DURKHEIM, E. As formas elementares da vida religiosa: o sistema totêmico na Austrália. São Paulo: Martins Fontes, 1996.

ELIADE, M. Tratado de história das religiões. Lisboa: Cosmos, 1977.

OLIVEIRA, L. B. et al. Ensino religioso: fundamentos e métodos. São Paulo: Cortez, 2007. (Coleção docência em formação. Série ensino fundamental).

Recebido: 20/04/2009

Receveid: 04/20/2009

Aprovado: 02/05/2009 Approved: 05/02/2009

Revisado: 15/07/2009 Reviewed: 07/15/2009 